\title{
Low-Income Housing in Nigeria: A liveability investigation
}

\author{
Mohammad Abdul Mohita, Sule Abbas lyandab \\ abInternational Islamic University Malaysia (IIUM), \\ Jalan Gombak, 53100 Kuala Lumpur, Malaysia \\ mamohit@iium.edu.my
}

\begin{abstract}
This paper examined the quality of life against the backdrop of the existing environment in the public low-income housing estates. Based on the desktop literature the study used both subjective and objective measurements to investigate the liveability of the selected housing estates. Home environment, neighbourhood amenities, economic vitality, social environment and civic protection were examined. The stratified random sampling was used in distributing questionnaire to household heads in all types of homes. Data were analysed with descriptive statistics and structural equation modelling (SEM). This study contributes to the existing body of knowledge in liveability studies in terms of model construct.
\end{abstract}

Keywords: Liveability; Low-income; Quality of life; SEM

eISSN: 2398-4279 @ 2017. The Authors. Published for AMER ABRA by e-International Publishing House, Ltd., UK. This is an open access article under the CC BY-NC-ND license (http://creativecommons.org/licenses/by-ncnd/4.0/). Peer-review under responsibility of AMER (Association of Malaysian Environment-Behaviour Researchers), ABRA (Association of Behavioural Researchers on Asians) and cE-Bs (Centre for EnvironmentBehaviour Studies), Faculty of Architecture, Planning \& Surveying, UniversitiTeknologi MARA, Malaysia. https://doi.org/10.21834/ajqol.v2i6.45 


\subsection{Introduction}

Liveability concept focused on human wellbeing in relation to living environment. As the city grows, the population pressure persists, and more house units are built to cater for the city dwellers. However, UN-Habitat, (2006) report shows over a billion people lives in slum condition all over the world. In 2013,65\% of Nigerians are reported living in slums which include formal and informal housing areas. (Yari, 2013). The question is what is the state of planned housing estates in our states of the federation? Both federal government and the state government have continuing building housing units for various levels of income groups (low, middle and high-income) in their respective territory. However, Niger state government efforts in the provision of public low-income housing in the state have not been investigated. This study therefore, investigates the liveability of the public low-income housing estates of Niger State, Nigeria.

\subsection{Aim}

This study examined the quality of life (QOL) against the backdrop of the living environment in the public low-income housing estates in Niger State of Nigeria.

\subsection{Objectives}

a) To develop a liveability framework with appropriate dimensions and indicators.

b) To find out the perception of the residents towards the liveability of the housing estates.

c) To establish factors that significantly influences the perception of the residents' level of satisfaction with their housing estate.

d) To validate the model framework of the study

\subsection{Literature Review}

- There is an abundance of discussion on liveability in the literature but a definition of the term is imprecise.

- The literature revealed that the study of liveability is not based on theory but empirical investigations (Omuta, 1988; Van den Heuvel, 2013)

- Extant literature shows that liveability study is similar to conducting QOL study and sustainability. However, distinctions have been made between the three concepts (VanZerr and Seskin, 2011; Lowe et al., 2013).

\subsection{Empirical review}

On the empirical study, Chaudhury (2005) examined the liveability of the capital city of Bangladesh, Dhaka and the third largest town in Bangladesh, Khulna. The evaluation focused on consumer goods, utility services, housing affordability (rent), social security and environmental conditions. The study findings showed that economic growth of Dhaka 
makes it more liveable than Khulna. However, the residents of Taman Melati in Kuala Lumpur Malaysia have expressed to continuing living in the area. The residents were satisfied with their living environment although their satisfaction was low on some physical environmental parameters such as noise pollution, air pollution and no brightness of streetlight at night. Non brightness of the streets light at night is link to insecurity of the resident at night (Abdul Azeez et al., 2010). Similarly, Azahan et al., (2009) affirmed that, Seremban in the state of Negeri, Malaysia has the potential to provide a better living condition to inhabitants if the planning authority takes cognisance of its potentialities. Also, urban density and liveability relationship of Fairfield, Newtown in New Zealand and Churton Park in Canada was investigated through a triangulation methodology i.e. quantitative, qualitative and literature review. The measured variables include; connectivity, accessibility, mixed use and density. The study results revealed that more amenities are needed in the area, and improvement of the existing facilities is required. However they (residents) believed their neighbourhood is liveable (Betanzo, 2009).

Omuta (1988) investigated the environmental problems of Benin City, Nigeria through conceptual standards such as employment, housing, amenity, education, nuisance and socio-economic dimensions. The study adopted stratified random sampling of which twentyone neighbourhoods of Benin City serves as units of assessment. The study analysis shows that the quality of life in the areas and overall environment and liveability of the city is too low. Asiyanbola et al., (2012) studied neighbourhoods' liveability of Ago-Iwoye and ljebu-lgbo in Ogun State, South-West Nigeria. The findings show that necessary facilities and amenities in the areas were in a disrepair state. Ekop (2012) conducted principal component analysis to explain the variability of the set of data input for housing quality of Calabar metropolis, Nigeria. The inter-correlations of the data set revealed that socioeconomic, housing characteristics and neighbourhood features are essential determinants of the liveability of the Calabar metropolis. However, away from informal housing environment/settlement, llesanmi (2012) examined the quality of public housing in Lagos state, Nigeria. His finding shows that public housing in Lagos State, Nigeria were of the low quality. Evidently, there is a dearth of study on the liveability of public low-income housing in Nigeria and this study tends to contribute in this regards. This study benefited from the operational definition of liveability in Flanders and the Netherlands through four dimensions namely: (a) Housing/dwelling quality (b) Physical environment quality i.e. level of utility services and facilities (c) Quality of the social environment (d) Safety of the neighbourhood (Heylen, 2006).

\subsection{Methodology}

Based on the literature reviewed the dimensions/indicators of liveability identified were grouped into six categories - socio-economic characteristics, economic vitality, housing characteristics, the safety situation, neighbourhood facilities, and social interaction. Thus, 
the questionnaire explicitly asks questions based on these categories that form the primary source of data and the questionnaire was based on 5-point Likert scale (Mohit and Hannan, 2010). Using stratified random sampling, a total of 400 homes were sampled out of 1000 housing units in three different locations. A total of 366 questionnaires were returned and the analysis conducted includes descriptive statistics, analysis of variance and confirmatory factor analysis.

\subsection{Results and Discussions}

\subsection{Socio-Economic Characteristics of the Respondents}

The descriptive statistics shows that $79 \%$ of the participants are males, and the remaining are females. About $83 \%$ are in the age of 31-60years and close to $94 \%$ obtained higher education. Approximately $70 \%$ are gainfully employed in both government and private sectors. $85 \%$ represents married class and the majority of them $62 \%$ have between $5-12$ members in the family while $58 \%$ of the families have only two persons working. However, $63 \%$ earned close to N100, 000.00 per month, $32 \%$ about N200, 000.00 monthly and the remaining $5 \%$ earned above N200, 000.00 monthly. Furthermore, $76 \%$ represent owners' occupied, and $24 \%$ are renters. Also, on the length of stay $73 \%$ indicates less than ten years while others have lived there between ten years and thirty years. In addition, $75 \%$ are from the state, and the other $25 \%$ are from other states of Nigeria.

\subsection{Respondents' liveability perception}

Table $1 \& 2$ shows the overall mean satisfaction for the location of the estates and residential types respectively. The mean satisfaction scores on the liveability dimensions/indicators of the residential environment as measured are shown in Table 3. From Table 1 it is evident that the respondents were satisfied with the location of their housing estates with mean satisfaction score of 3.33 for both M.I. Wushishi and Bosso Estates while the Tunga Low-Cost housing estates mean satisfaction score is 3.45 . In addition, respondents are satisfied with the provision of the two and three bedrooms originally constructed with an average value of 3.30 and 3.43 respectively. However; it seems four bedrooms and above is preferable given the average score of those who have added to the number of bedrooms to be 3.82 .

Table 1. Housing Estates

\begin{tabular}{|l|l|l|l|}
\hline Name & Mean & N & S.D \\
\hline M.I. Wushishi & 3.33 & 132 & 0.673 \\
\hline Bosso Estate & 3.33 & 115 & 0.697 \\
\hline Tunga Low Cost & 3.45 & 118 & 0.635 \\
\hline
\end{tabular}


Table 2. Residential types

\begin{tabular}{|l|l|l|l|}
\hline Bungalow & Mean & N & S.D \\
\hline Two Bedrooms & 3.30 & 227 & 0.672 \\
\hline Three Bedrooms & 3.43 & 121 & 0.656 \\
\hline Four Bedrooms \& Above & 3.82 & 17 & 0.529 \\
\hline
\end{tabular}

Table 3. Liveability dimensions and satisfaction mean constructs

\begin{tabular}{|l|l|l|l|}
\hline Satisfaction constructs & Mean & N & S.D \\
\hline Housing characteristics & 3.40 & 366 & 0.477 \\
\hline Neighbourhood facilities & 2.71 & 365 & 0.412 \\
\hline Safety environment & 2.97 & 366 & 0.478 \\
\hline Economic vitality & 3.41 & 366 & 0.757 \\
\hline Social interaction & 2.64 & 365 & 0.477 \\
\hline
\end{tabular}

From the Table 3 it is evident that the respondents are satisfied with their economic vitality and housing unit characteristics with mean values of 3.41 and 3.40 respectively. These means that respondents are contended with what they are earning and not affected either by being paying housing loan or being a renter. On the other hand, the respondents express low satisfaction with the following; safety situation, neighbourhood facilities and social interaction with mean values of 2.97, 2.71 and 2.64 respectively. Similar result was found in the study by Ismail et al. (2015) in Malaysia. Further analysis shows that, very low satisfaction expressed by the respondents is attributed to unavailability of some fundamental amenities in the neighbourhoods and lack of preventive measures for safety. For example, no police protection and fire-fighter services in the selected estates. There is also a lack of open spaces, recreational ground for interaction in the estates.

\subsection{Factors influencing respondents' liveability perception}

Analysis of variance (ANOVA) was conducted to explore those factors that influence the respondents' perception of the liveability of their housing environment. The independent variables being 11 socio-economic characteristics (age, gender, marital status, household size, indigene-ship, education, employment status, number of working class, monthly income, length of stay and tenure status) and dependent variable- perception of liveability. In these only two variables were found to have influenced the respondents' perception of liveability of their living environment, these are age bracket with $\mathrm{F}$-cal $(4,360)=2.450$, Pvalue $=0.046$, and employment status as $\mathrm{F}$-cal $(4,360)=3.079, \quad P$-value $=0.016$. This result corroborates the findings of the study of liveability of the City of Bhopal, India by Pandey et al. (2014). However, other socio-economic characteristics factors have their Pvalues $>0.05$ and therefore do not have effect on the residents' perception of liveability of their housing estates. Similar findings were reported in the study by Li et al. (2012). 


\subsection{Confirmatory Based-Structural Equation Modelling (CB-SEM)}

The confirmatory factor analysis of five-factor constructs of liveability was analyzed with the statistical package for the social science (SPSS version 22) and Analysis of Moment Structure (AMOS version 22) software. Based on conventional criteria as found in the literature such as RMSEA value should be $>0.05$ (Marques et al, 2015). The CFI cut off > 0.9 (Navabakhsh and Motlaq, 2009). Also checked were outliers, normality distribution Skewness and Kurtosis, and Multivariate normality (Adul Malek et al., 2009; Marques et al., 2015).

In the hypothesized model of 40 items with five constructs (Model 1), the model result indicates poor model fit. Adul Malek et al., (2009) and Marques et al., (2015) opined that the model should be modified until a 'fit' model is achieved. The factors with unacceptable factor weights were removed (i.e. factor $<0.6$ ). And the modified model was tested (Model 2), although model two was found to be fit but with a factor weight on social interaction $>1$. The standardize factor loading should be between -1 and +1 . One of the remaining twofactor loadings of social interaction has a loading of -1.09 ; therefore the construct of social interaction failed construct reliability and was removed. Hence, the test of the third model and it revealed goodness-of-fit (see Table 4) considering all criterion above as suggested by many authors. However, Table 5 shows the indicators/measurement items of the construct.

Table 4. Hypothesized models fit $(n=366)$

\begin{tabular}{cccccc}
\hline & Chi-square & P-value & $\begin{array}{c}\text { Normed chi- } \\
\text { square }\end{array}$ & CFI & RMSEA \\
\hline Model 1 & 4300.319 & 0.000 & 5.883 & 0.615 & 0.116 \\
Model 2 & 515.028 & 0.000 & 3.627 & 0.913 & 0.085 \\
Model 3 & 617.248 & 0.000 & 2.731 & 0.903 & 0.069 \\
\hline Note: CFI= Comparative Fit Index; RMSEA $=$ Root Mean Square of Approximation.
\end{tabular}

Table 5. Indicators/measurement items of the constructs

\begin{tabular}{lll}
\hline Constructs & Factor & Description \\
\hline Housing characteristics (H_Environ) & HE1 & Housing unit size \\
& HE2 & Living size area \\
& HE3 & Dining area size \\
& HE4 & Bedrooms size \\
& HE5 & Kitchen size \\
& HE6 & Toilet and bath size \\
Economic vital (E_vital) & HE9 & Affordability \\
& EV1 & Total monthly income \\
& EV2 & Public transport accessibility \\
& EV5 & Effects of loan/rent on total income \\
Neighbourhood facilities (N_facity) & EV6 & Standard of living \\
& NF1 & Children education services \\
& NF2 & Health care services \\
& NF3 & Garbage collection \\
Safety situation (S_environ) & NF6 & Recreational facilities \\
& SE1 & Safety of life and property \\
& SE2 & Availability of security services \\
\hline
\end{tabular}




\subsection{Conclusion}

Firstly, the dimensions and indicators of measuring liveability of housing environment were established through the literature review as this leads to the construct of a conceptual framework for the study.

Secondly, from the survey data, all the respondents were satisfied with the location of their housing estates (see Table 1). However, this finding contrasts with the results of Olotuah and Bobadoye (2009) which revealed public housings are located in the remote area, and therefore people are dissatisfied with the location. Also, respondents perceived their types of housing units reasonably adequate. Furthermore, analysis of the liveability dimensions construct shows that respondents are satisfied with the affordability of the housing units. On this either paying house loan or being a renter does not have an effect on the respondents' household income for their livelihood. However, low satisfaction was recorded in relation to the safety situation; neighbourhood facilities and social interaction (see Table 3). Therefore, it is recommended that the government should be pro-active in securing the life and properties in the state. Not only guarantee the life and properties but also adequate neighbourhood facilities and maintenance strategies should be in place.

Thirdly, an analysis of variance (ANOVA) conducted shows that only two out of eleven demographic characteristics of the respondents influence their perception of liveability of their housing estates. The two demographic characteristics are age brackets and employment status. Other socio-economic features of the respondents are not significantly influencing their liveability perception, age and employment status explained about $16 \%$ and $17 \%$ variations respectively in the perception of liveability of their housing environment. This implies that the housing need/required is predicted by age and employment status.

Fourthly, the CFA results of the hypothesized models revealed that a four-factor model with seventeen indicators (Model 3) provides an adequate fit to the data. This finding affirmed that the liveability assessment variables used satisfied both the internal reliability and the construct validity, hence validates the theoretical model (Model 3). Conclusively, from the analysis it is important that the government consider the findings of this research so as to improve the quality of life of the residents of the selected public housing estates in the state. It can be achieved by providing neighbourhood facilities and improve safety measures in the housing estates. Also for future housing development, it is important to consider homes development beyond two and three bedrooms so as to cater for large families.

\section{References}

Abdul Azeez, K. H., Miura, M., Inokuma, S., and Nishimura, Y. (2010). Perception analysis of living environment at Taman Melati residential area.

http://fbe.um.edu.my/images/fab/Files/JDBEVOL7/vol7-01.pdf. 
Abdul Malek, N., Mariapan, M., and Mohd Shariff, M. K. (2012). The making of a quality neighbourhood park: A path model approach. Procedia - Social and Behavioural Sciences 49 Pp202 - 214.

Asiyanbola, R., Raji, B. and Shaibu, G. (2012). Urban liveability in Nigeria- A pilot study of Ago-lwoye and ljebuIgbo in Ogun State. Journal of Environmental Science and Engineering Pp 1203-1213.

Azahan, A., Jamaluddin, M.J., Lukman, Z. M., Kadaruddin, A. and Kadir, A. (2009). The quality of life in Malaysia's intermediate city: Urban dwellers perspective. European Journal of Social Sciences - Volume 9, Number 1.

Betanzo, D. M. (2009). Exploring density liveability relationships. The Built \& Human Environment Review, Volume 2, Special Issue 1, 2009.

Chaudhury, A. H. (2005). Urban liveability, decentralisation and development: A comparative study on Dhaka and Khulna cities URP Discipline, Khulna University.

Ekop, G. (2012). An assessment of the interrelationships among housing quality variable sets in Calabar metropolis. Journal of Geography and Regional Planning Vol. 5(14), pp. 375-380.

Heylen, K. (2006). Liveability in social housing: three case-studies in Flanders. Residential Environments and People, ENHR Conference July 2006. Ljubljana, Slovenia.

llesanmi, A.O. (2012). Housing, neighbourhood quality and quality of life in public housing in Lagos, Nigeria, International Journal for Housing Science, Vol.36, No.4 Pp.231-240.

Ismail, F., Jabar, I. L., Janipha, N. A. I. and Razali, R. (2015). Measuring the quality of life in low cost residential environment. Procedia - Social and Behavioral Sciences 168, Pp270 - 279.

Li, C., Sun, L. and Jones, P. (2012). Liveability of high-rise housing estates: A resident-centred high-rise residential environment evaluation in Tianjin, China, 48th ISOCARP Congress 2012.

Lowe, M., Whitzman, C., Badland, H., Davern, M., Hes, D., Aye, L., Butterworth, I. and Giles-Corti, B. (2013), Liveable, healthy, sustainable: What are the key indicators for Melbourne neighbourhoods? Research Paper 1, Place, Health and Liveability Research Program, University of Melbourne http://mccaugheycentre.unimelb.edu.au/research/health_and_liveability.

Marques, D., Pinheiro, M. R., Matos, A. P., and Marques, C. (2015). Confirmatory factor analysis of the QRI Father's Version in a Portuguese sample of adolescents. Procedia -Social and Behavioral Sciences 165 Pp 267 274.

Mohit, M. A. and Hannan, M. H. E. (2012). A study of crime potentials in Taman Melati terrace housing in Kuala Lumpur: Issues and challenges. Procedia - Social and Behavioral Sciences 42 Pp 271 - 283.

Navabakhsh, M. and Motlaq, M. (2009). Effects of urban information and communication technology on sustainable development. Journal of Food, Agriculture \& Environment Vol.7 (3\&4) Pp8 91 - 89 7. www.worldfood.net.

Olotuah, A.O. and Bobadoye, S.A. (2009). Sustainable housing provision for the urban poor: A review of public sector intervention in Nigeria, The Built and Human Environment Review, Volume 2, Pp 51 -63.

Omuta, G.E.D. (1988). The quality of urban life and the perception of liveability: A case study of neighbourhoods in Benin City, Nigeria. Social Indicators Research 20 Pp417-440. 
Pandey, R.U., Garg, Y.G. and Bharat, A. (2014). Understanding dependency of liveability on socio-economic and demographic parameters. International Journal of Humanities and Social Sciences (IJHSS), Volume 3, Issue: 1 Pp61-68.

UN-Habitat (2006). Regulatory framework and strategic urban planning and management; Conference paper on housing and urban development, Nairobi, 3 -4 April. www.unhabitat.org.

Van den Heuvel, N. (2013), A conceptual analysis of liveability and the translation of liveability into policy; A case study of Bogotá.

VanZerr, M., and S. Seskin (2011),Recommendations Memo \#2 Livability and Quality of Life Indicators. CH2M Hill, Portland.

Yari, K.M. (2013), Nigerians Still live in Slum Conditions-UN. Blueprint Newspaper http://blueprintng.com/new/2013/07/09/69-70-of-nigerians-still-live-in-slum-conditions-un/ [Accessed on 8/10/13] 